\title{
LA ROPA DEL QUINTERO (JAMMĀS) SEGÚN UNA FETUA DE AL-QAWRĪ (s. XV)*
}

\author{
CLOTHES OF THE FARMER (KHAMMĀS) \\ ACCORDING TO A FATWÀ BY AL-QAWRĪ (s. XV)
}

\author{
Inmaculada CAmarero Castellano ${ }^{1}$ \\ Universidad de La Laguna
}

Una fetua de al-Qawrī (s. Xv) recogida en $a l-M i{ }^{\complement} y \bar{a} r$ de al-Wanšarīsī responde a varias cuestiones relacionadas con el contrato de aparcería en tierra de secano (muzāra $a$ ) establecida entre el dueño de la tierra y el quintero (jammās). En una de ellas se pide la legalidad para que este aparcero sin recursos exija una prenda de ropa $(k-b b-5)$ a su «socio», tal y como en otras ocasiones se le ha permitido solicitar la ŷallābiyya y el salhām/silhām. Hasta la fecha, el término $k-b b-s ̌$ no se haya registrado bajo esta forma en otro lugar. En este trabajo se plantea la posibilidad de que se trate de dos fetuas diferentes y se pone en cuestión la edición moderna de Rabat, que no se ajusta a la de Fez. Para terminar, se marcan las diferencias con respecto a la interpretación y traducción que de esta fetua ha realizado $\mathrm{V}$. Lagardère.

Palabras clave: Fetua; al-Qawrī; al-Wanšarīšī; aparcería; quintero; $k-b b-\check{s}$.
This article focuses on a fatwa written by the fifteenth-century Muslim jurist al-Qarawī, which is included in al-Wansharīsî's al$M i$ 'yar. In this fatwā al-Qarawī responds to various questions regarding the making of a contract for labour upon unirrigated land (muzāra'a) between the landowner and his tenant. Among the questions received on this matter, a request is made for an impoverished landowner to have the right to demand from his tenant the jalläbiyya and the salhām/ silhām. Hitherto the term $k-b b$-sh had not been documented anywhere else under this form. This article suggests that this fatwa contains not one, but rather two distinct fatwā-s. It also takes issue with the differences between the editions of al-Mi'yar made in Rabat and Fez. Finally, it highlights the various translations and interpretations of the fatwa and the many divergences between them.

Key words: Fatwā; al-Qawrī; al-Wansharīsī; Partnership; Farmer; $k-b b-s ̌$.

* Este trabajo se enmarca dentro del Proyecto de Investigación "Análisis histórico de la influencia ideológica en la investigación de los arabismos. El caso del español de Canarias" ( $\mathrm{n}^{\mathrm{o}}$ 1802220501), financiado por el Vicerrectorado de Investigación y Desarrollo Tecnológico de la Universidad de La Laguna. Investigador principal: D. Serrano Niza.

${ }^{1}$ Miembro del Grupo de Investigación "Estudios Árabes e Islámicos” (ESARIS) de la Universidad de La Laguna. 


\section{Introducción}

Durante la fase de recopilación y análisis de fuentes referidas a la muzāra'a o contrato de siembra ${ }^{2}$, me llamó la atención una fetua emitida en el Magreb, recogida por al-Wanšarīs $\overline{1}^{3}$ y analizada por V. Lagardère, que tenía como fin regular la ropa que el jammās o quintero había de recibir por parte del dueño de la tierra en la cual trabajaba. En concreto, quiero referirme a la interpretación y traducción de uno de los términos que se citaban en dicha fetua, a saber, la prenda llamada $k-b b-\check{s}$. Una vez localizado el texto árabe en su edición de Rabat y comprobadas las diferencias que había con respecto al de la edición antigua de Fez, consideré conveniente hacer un paréntesis en la tesis y dedicar mi trabajo a este dictamen que tanta información ha proporcionado.

Este estudio se iniciará localizando al autor de la obra donde la fetua se halla recogida, para continuar con la identificación del jurista que la emitió en el s. Xv. Posteriormente, tras delimitar qué es la muzāra'a y su variante jamāsa dentro de los contratos agrícolas que estuvieron en vigor en al-Andalus y en el Magreb, este trabajo se centrará en el texto mismo de la fetua, en sus dos ediciones de Rabat y Fez y en la traducción de ambas. Para terminar, se ofrecerá un apartado donde se argumentan todos los errores que he observado en la interpretación que Lagardère hace de esta fetua.

2 El estudio del contrato de muzāra'a forma parte de la tesis que estoy realizando, titulada "Ley islámica y el medio rural. Teoría y práctica legal en la agricultura de alAndalus", dirigida por María Arcas Campoy y Expiración García Sánchez. Está becada por la Dirección General de Universidades e Investigación. Consejería de Educación, Cultura y Deportes del Gobierno de Canarias.

3 Existen dos ediciones de esta obra: una antigua litografiada, de editor anónimo, Fez, 1896-1898, 12 vols. y una edición más reciente realizada por M. Haŷŷ̀ et alii, Rabat-Beirut, Wizārat al-Awqāf-Dār al-Garb al-Islamī, 1981-1983. Está traducida, analizada y resumida parcialmente por Amar, E., "La pierre de touche des fetwas d'Ahmad al-Wanšarīsı̄”, Archives Marocaines, XII y XIII, París, 1908, y por Lagardère, V., Histoire et société en Occident musulman au moyen âge. Analyse du Mi 'yār d'al-Wanšarīsī, Madrid, 1995. Igualmente, ha sido objeto de la tesis doctoral de Vidal Castro, F., Economía y sociedad en al-Andalus y el Magreb a través de una fuente jurídica: el Mi'yār de al-Wanšarīisi (m. 914/1508). Estudio especial del agua, Granada, 1992, editada en microfichas. 


\section{La fetua de al-Qawrī en al-Mi yār de al-Wanšarīsī}

La fetua objeto del estudio ha sido extraída de la obra titulada

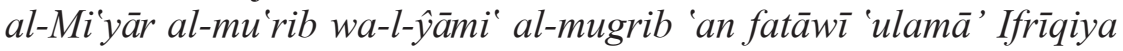
wa-l-Andalus wa-l-Magrib, realizada por el magrebí al-Wanšarīs̄i (m. 914/1508) ${ }^{4}$.

El autor de la fetua es el jurista marroquí Abū 'Abd Allāh Muhammad b. Qāsim b. Muhammad b. Aḥmad al-Andalusī al-Qawrī al-Lajmī al-Miknāsi al-Fāsī, nacido a comienzos del s. Ix h. en Mekinez. Posteriormente se trasladó a Fez para dedicarse a la enseñanza y allí ejerció la función de muftī. En esta ciudad fue alumno, entre otros, de 'Imrān b. Mūsà al-Ŷānātī, de quien tomó la riwāya de la Mudawwana que él aprendió de su maestro Mūsà al-'Abdūsī, cuya cadena de transmisión se remontaba al propio Saḥnūn. Murió a mediados de $\underline{d} \bar{u}$ l-qa'da de 872/comienzos de junio de $1468{ }^{5}$.

\section{Sobre muz̄ära $a$, jamāsa y jammās}

En esta fetua la cuestión que se le plantea a al-Qawrī gira en torno a la indumentaria que puede exigir el quintero (jammās) al dueño de la tierra. De las tres prendas que se citan, a saber, el $k-b b-\breve{s}$, la ýallābiyya y el salhām/silhām, merece una especial atención la primera de ellas, ya que hasta ahora no se halla documentada en ninguna fuente árabe bajo esta forma. Por esa razón, este hápax aparecerá en este trabajo sin vocalizar ${ }^{6}$. También es importante porque Lagardère

${ }^{4}$ Vidal Castro, F., “Aḥmad al-Wanšarīsī (m. 914/1508): Principales aspectos de su vida", Al Qanțara, XII (1991), 315-352.

5 Para su biografía, véase Rodríguez Mediano, F., Familias de Fez (ss. XV-XVII), Madrid, 1995, 224-226. Agradezco la ayuda que me prestó Amalia Zomeño para localizar la bibliografía del autor de la fetua.

${ }^{6}$ Para el estudio del término $k-b b-s ̌$, quizá la obra más completa sea Simonet, F.J., Glosario de voces ibéricas y latinas usadas entre los mozárabes, Madrid, 1888, 98, s.v., CAPÚX/CAPÚS, “capucium, caparon”. Consúltese igualmente, Niermeyer, J.F., Mediae latinitatis lexicon minus, Leyden, 2002, I, 186, s.v., caputium, "*collet de tunique ou de manteau"/"capuchón", "capuce de moine". Hay registradas formas parecidas, como la que recoge Dozy, R., Supplément aux dictionnaires arabes, Beirut, 1991, II, 447, s.v., kabbus, "chaperon, capuchón". Por otro lado, en el diccionario de Ibn Manẓūr se cita tawb akbāss, que hace referencia tanto a «un tipo de vestido del Yemen» como a «un traje hecho jirones», pero no parece tener relación alguna con nuestro término. Véase Ibn Manz̄ūr, Lisān al-'Arab, ed. Dār al-Ŷ̄̄l y Dār Lisān al-'arab, Beirut, 1988, 213-214. En el diccionario de Lane, E.W., Arabic-English Lexicon, Londres, 1877, no hemos en- 
no supo interpretarlo correctamente ${ }^{7}$ y lo tradujo por «houe» ("azadón"), un instrumento de labranza, cuya presencia no tiene sentido junto a las prendas de ropa solicitadas, como más tarde veremos.

Antes de entrar de lleno en el texto de la fetua y con el fin de lograr una mayor comprensión, he creído conveniente, a pesar de que son conceptos conocidos, exponer brevemente las características esenciales de la muzāra'a, de la jamāsa y del jammās.

Muzāra'a: es la sociedad (šarika/širka) contraída entre el dueño de la tierra y su aparcero con el fin de llevar a cabo la siembra, el cuidado y la recogida de cereales, legumbres y demás granos. Este contrato, llamado también "de siembra», se establece por un período que depende exclusivamente de la maduración de la cosecha y se realiza siempre en tierra de secano.

Normalmente la sociedad se concebía de esta manera: el aparcero y el propietario aportan la semilla a partes iguales, mientras que lo habitual era que únicamente el primero fuese quien realizara las labores del campo. Los aperos de labranza, los bueyes y la mano de obra asalariada, en caso de que ésta se necesite, pueden ser aportados por uno de ellos solamente. De esta manera, la cosecha resultante se repartirá entre los dos socios, tal y como hubieran convenido el día del contrato que, en la mayoría de los casos, es proporcional a las aportaciones que ambos hayan hecho en la sociedad. Este tipo de contrato generó mucha polémica entre los juristas, pues el hecho de que a cada uno de los socios le corresponda una parte indeterminada de la cosecha es calificado como garar u operación aleatoria, que está prohibida por el Islam. No obstante, los juristas musulmanes, presionados por la necesidad social y económica, tuvieron que ceder y legalizar la muzāra'a y permitir que se establecieran contratos de este tipo, donde ya las aportaciones no eran iguales sino equivalentes e, incluso, llegaron a conceder que se formaran sociedades en las que ni siquiera existía este equilibrio.

contrado ningún resultado en las raíces $k-b-s$ y $k-b-\check{s}$. Tampoco queda registrada ninguna prenda de ropa bajo esas formas consonánticas en el diccionario especializado de Dozy, R., Dictionnaire détaillé des noms des vêtements chez les arabes, Amsterdan, 1845, reimp. Beirut, s.d. No obstante, el estudio etimológico del término $k-b b-s ̌$ junto con el de las características formales de dicha prenda es un trabajo que requiere una dedicación especial y más detallada. Por tanto, queda pendiente para otra ocasión.

${ }^{7}$ Lagardère, Histoire et société, 333-334, no 178.

Al-Qanțara (AQ) XXX 2, julio-diciembre 2009, pp. 447-465 ISSN 0211-3589 
Tanto en al-Andalus como en el Magreb, el fiqh dio libertad para que ambos contratantes se asociaran de la forma en la que ellos consideraran conveniente. El resultado fue el establecimiento de cinco contratos distintos dentro de la muzāra'a, cuya diferencia esencial radicaba en la proporción de grano que recibiría el aparcero al término de la cosecha. De este modo, se legalizaron los siguientes tipos de contrato de siembra: aparcería a medias (muzāra'a 'alà l-nușf o munāṣafa), aparcería al tercio (muzāra'a 'alà l-tulț o muțālata), aparcería al cuarto (muzāra'a 'alà l-rub' o murāba'a), aparcería al quinto (muzāra'a 'alà l-jums o jamāsa/jimāsa) y, por último, aparcería al sexto (muzāra'a 'alà l-suds) ${ }^{8}$.

Jamās $a^{9}$ : como he señalado anteriormente, el contrato de nuestra fetua es el denominado muzāra $a$ al quinto o jamāsa, cuyas características son muy distintas a las de los otros contratos de tipo muzāra'a anteriormente señalados. En aquellos otros, el aparcero aporta una parte de semilla, la que le corresponde según el tipo de contrato que haya firmado. Es decir, si ha formado con el dueño de la tierra una murāba $a$, el trabajador aporta un cuarto de semilla a la sociedad, y si ha establecido una mutālața, éste aporta un tercio de la semilla; sin embargo, en caso de que se establezca una jamāsa, el aparcero no pone nada más que su trabajo y el dueño de la tierra todo lo demás. Este último dato es importante para la fetua que nos ocupa, como ya veremos. Como pago, el aparcero jammās recibe la quinta parte de la cosecha y, puesto que ésta es una cantidad indeterminada considerada ilegal para el Islam, los juristas obligan a que los contratantes expresen en el contrato que, en realidad, se trata de una sociedad, en donde se haga constar que el valor del trabajo aportado por el quintero es igual a la otra parte correspondiente a su socio.

Dentro de la muzāra'a, éste es el contrato más polémico, porque por su origen y naturaleza es extraño al derecho islámico. Se considera herencia del antiguo colonato romano e influenciado por el uso bereber del s. XI. La muzāra'a 'alà l-jums fue legalizada en la mayo-

8 Para una visión general del concepto de la muzāra $a$, véase, Camarero Castellano, I., "El concepto del contrato de aparcería llamado muzāra'a, según los juristas malikíes de al-Andalus (s. VIII-XV)", BAEO, XXXVIII (2002), 181-198.

9 Para la jamāsa, consúltese Brunschvig, R., "Contribution a l'histoire du contrat de Khamessat en Afrique du Nord", Revue Algérienne, Tunisienne et Marocaine de Législation et de Jurisprudence, 1931, 17-21, en Études sur l'Islam classique et l'Afrique du nord, I, London, 1986. 
ría de los casos porque, como dice Sahnūn, se basa en una necesidad (darūra) y tiene como fundamento la ley consuetudinaria ('urf) ${ }^{10}$.

Jammās: el aparcero jammās, calificado en una fetua de al-Burzulī (841/1438) como da'îf (pl., du'afä', «pobre», «débil») ${ }^{11}$, es aquel labrador que no tiene medios económicos para aportar en la sociedad nada más que su trabajo y, aunque para Saḥnūn e Ibn al-Qāsim el quintero debe contribuir además con los bueyes, reconocen que en Ifrīqiya la costumbre ('urf) es que sólo colabore trabajando. Esto mismo lo afirma una fetua de Ibn Rušd ${ }^{12}$. En la práctica, tanto en alAndalus como en el Magreb se ha obligado al jammās a realizar todo tipo de trabajos, a diferencia de los otros aparceros. Lo más usual es que su labor consistiera en arar, escardar, quitar hierbas, cosechar, trillar, aventar y transportar el grano a los depósitos. No obstante, los textos jurídicos transmiten la polémica surgida a raíz de exigirle que, además, atendiera y alimentara los bueyes, recogiera leña y agua, se cuidara del vallado del campo y lo vigilara, y también previniera las calamidades agrícolas, como, por ejemplo, el daño de los pájaros ${ }^{13}$. Ibn Mugīt es uno de los juristas que se niega a que el quintero sea obligado a recoger leña ${ }^{14}$. Al-Burzulī, por su parte, denuncia los abusos a los que están sometidos los quinteros en Túnez, ya que la mayoría de los propietarios les obligaban a que renunciaran a la mitad de la paja resultante de la cosecha, les exigían que cuidaran de sus bestias, que recogieran leña y que sacaran agua ${ }^{15}$. También sabemos que algunos juristas permitieron que, dentro de la jamāsa, se les obligara a construir edificios, fosos o pozos, aunque la mayoría de ellos consideraba que éstas no eran labores agrícolas propiamente dichas y que deberían serles pagadas aparte por el propietario ${ }^{16}$.

${ }^{10}$ Santillana, D., Istituzioni di diritto musulmano malichita con riguardo anche al sistema sciafiita (vol. I, ed. 1926 y vol. II, ed., 1938), Roma, II, 308.

${ }^{11}$ Al-Wanšarīsī, al-Mi'yār, ed. Rabat, VIII, 149-150; ed. Fez, VIII, 96-97; Lagardère, Histoire et société, 324-325, $\mathrm{n}^{\mathrm{o}} 141$.

${ }^{12}$ Ibn Rušd, Fatāwà, al-Talīlì (ed.), Beirut, 1987, I, 357, no 287. De igual modo, está recogida en al-Wanšarīsī, al-Mi'yār, ed. Rabat, VIII, 152-153; ed. Fez, VIII, 98-99; Lagardère, V., Histoire et société, 321, n 123 , y 357-358, $\mathrm{n}^{\circ} 287$.

${ }_{13}^{13}$ Véanse estas obligaciones en nuestra fetua, al-Wanšarīsī, al-Mi yār r, ed. Rabat, VIII, 150-151; ed. Fez, VIII, 97-98.

${ }^{14}$ Ibn Mugīt, al-Muqni' fì 'ilm al-šurūt, F.J. Aguirre (ed.), Madrid, 1994, 265.

${ }^{15}$ Al-Wanšarīsī, al-Mi'yār, ed. Rabat, VIII, 149-150; ed. Fez, VIII, 96-97; Lagardère, Histoire et société, 324-325, $\mathrm{n}^{\circ} 141$.

${ }^{16}$ Así lo afirma Santillana, Istituzioni, II, 309.

Al-Qanțara (AQ) XXX 2, julio-diciembre 2009, pp. 447-465 ISSN 0211-3589 
Por último, como colofón a este apartado y citando de nuevo la fetua de al-Burzulī, hay que señalar que éste es el único dictamen jurídico, junto con el de al-Qawrī, en el que se encuentran referencias a la ropa del quintero. En aquél recoge la opinión del jurista de Cairuán, Abū Muḥammad al-Šabībī (m. 782/1380), quien no está de acuerdo con que el quintero reciba ropa o alimentos, ya que, según su parecer, son retribuciones que no forman parte de la sociedad. A raíz del vestuario y de la comida exigidas dentro de la jamāsa surgirían dos opiniones contrarias, una autorizándola y otra condenándola, aunque la tendencia mayoritaria fue su legalización, tal y como podemos ver en estas dos fetuas recogidas por al-Wanšarīsì.

\section{La fetua de al-Qawrī ${ }^{17}$}

\section{a) Contenido}

Hay que señalar que, de las dos ediciones que se conocen de al$M i$ ya $\bar{a}$, este estudio se ha realizado tomando como base la edición litografiada de Fez.

La frase escrita en el margen izquierdo del texto: "La cuestión del quintero (mas 'alat al-jammās)" da título a la fetua de al-Qawrī.

Diversos temas forman esta fetua, aunque sólo uno de ellos es el objeto de este trabajo: el referente a la indumentaria del quintero. Así pues, dentro de la totalidad del dictamen atribuido al muftí alQawrī se dan las siguientes resoluciones:

La muzāra'a al quinto debe ser tratada como una asociación (širka).

Se admite que el quintero reciba el quinto de la cosecha, aunque sea una cantidad indeterminada, siempre que se haga constar que el total de grano que va a recibir equivale al trabajo desempeñado en esa tierra.

Las obligaciones del quintero son solamente las de arar, escardar, quitar las hierbas, cosechar, trillar, aventar y transportar el grano a los depósitos adecuados, a pesar de que en el campo (bādiya) se tenga la costumbre de exigirle además otras labores.

La indumentaria exigida por el quintero son estas prendas: el $k$ $b b-\check{s}$, la ŷallābiyya y el salhām.

${ }^{17}$ Al-Wanšarīsī, al-Mi'yār, ed. Rabat, VIII, 150-151; ed. Fez, VIII, 97-98. Agradezco a Jesús García, de la Biblioteca del Instituto de Filología del CSIC en Madrid, que me proporcionara las páginas de la edición de Fez de esta obra. 
Si las circunstancias lo exigen, el quintero puede pedirle al dueño de la tierra un adelanto del grano o incluso la venta del mismo.

La paja resultante se divide entre el jammās y el dueño de la tierra en la misma proporción que el reparto de la cosecha.

\section{b) Texto árabe}

Las ediciones consultadas, como se ha indicado, son la edición litografiada de Fez, realizada en el s. XIX y la más reciente de Rabat. En la imagen que figura a continuación se observa, comparando los dos textos, cómo el de la edición de Rabat se halla reducido, habiéndose incorporado el texto que figuraba escrito al margen en la edición de Fez, sin que aparezca ninguna nota a pie de página explicando la existencia de este texto lateral. Por ello, a tenor de este ejemplo e imaginando que no es el único caso en el que hay errores, opino que la edición de Rabat no es totalmente fiel a la fuente árabe.

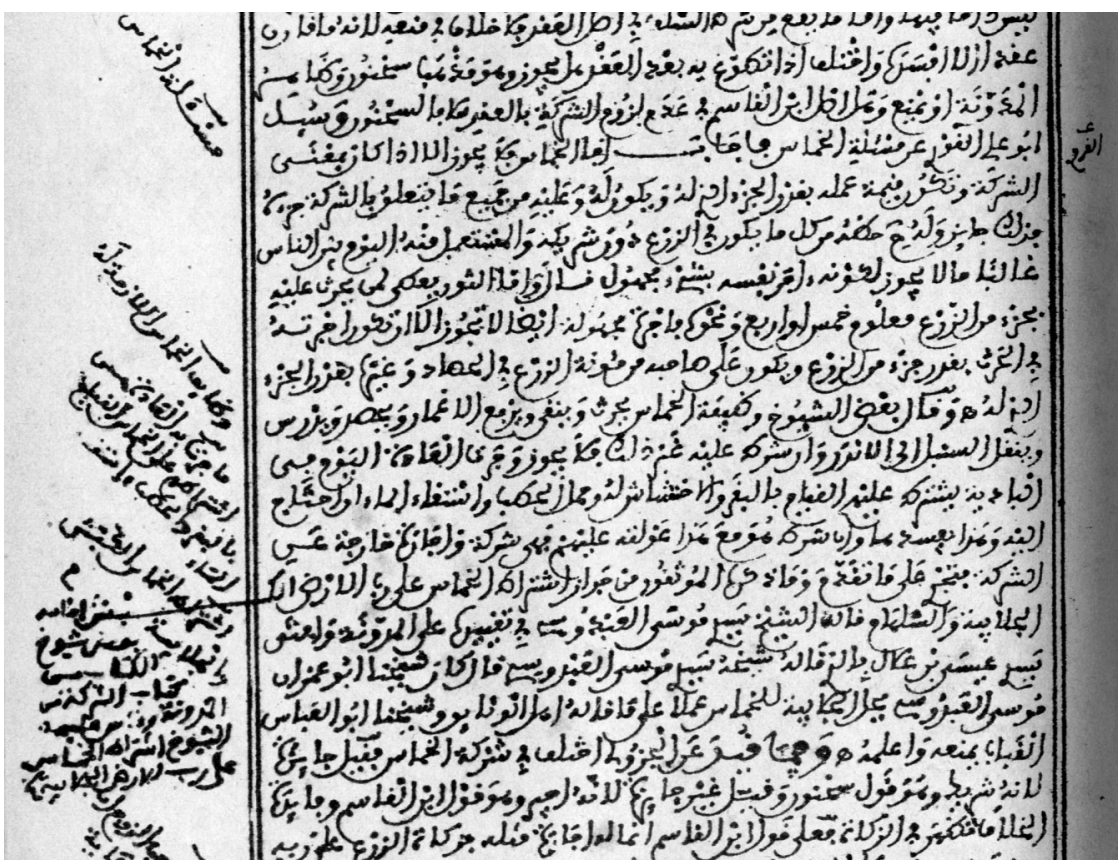

Al-Qanțara (AQ) XXX 2, julio-diciembre 2009, pp. 447-465 ISSN 0211-3589 


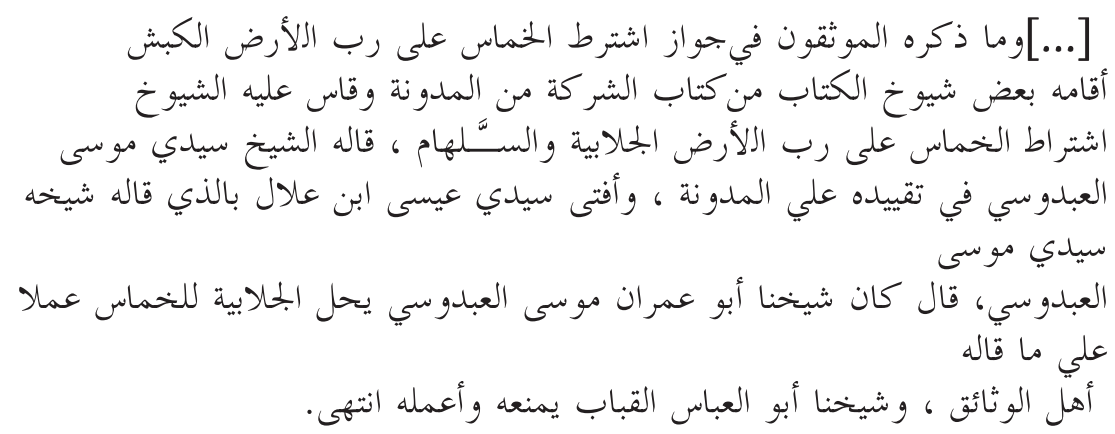

\section{c) Traducción}

En la traducción realizada se ha trabajado tanto con el texto contenido entre los márgenes como con las anotaciones escritas fuera de ellos, ya que estas notas laterales contienen una información muy valiosa y constituyen el núcleo y el tema principal de nuestro estudio.

Texto recogido dentro de los márgenes $[\ldots]$.

Se preguntó a Abū 'Alī al-Qawrī sobre la cuestión del quintero

Los notarios (muwattiqūn) consideran lícito que el quintero ponga como condición al dueño de la tierra [que le proporcione] [...] la ŷallābiyya y el salhām. Ésta es la opinión del šayj Mūsà al-'Abdūsī en su obra Taqyìd 'alà l-Mudawwana.

'Isà b. 'Allāl promulgó una fetua según la opinión de su maestro Mūsà al-'Abdūsī, que dice: "Nuestro šayj Abū 'Imrān Mūsà al'Abdūsī dio por lícito que se le proporcionara al quintero la yallābiyya, de acuerdo con la opinión que tienen los redactores de las actas (ahl al-watāa' 'iq $)^{18}$. Sin embargo, nuestro šayj Abū l-'Abbās al-Qabbāb se opuso a esto (yamna'u-hu) y así lo dio a conocer (a'lama-hu)».

Texto fuera del margen ${ }^{19}$

Cuestión del quintero (mas'alat al-jammās).

${ }^{18}$ Así aparece en la edición de Fez. En la de Rabat, ahl al-wata $a$ 'iq.

${ }^{19} \mathrm{He}$ de aclarar que va en dobles corchetes parte del texto escrito fuera del margen que he traducido anteriormente y que se aprovecha en esta segunda fetua que se cuestiona en el lateral de la página.

Al-Qanțara (AQ) XXX 2, julio-diciembre 2009, pp. 447-465 ISSN 0211-3589 


\section{Al-Qarawī.}

La condición del quintero de [exigirle al dueño de la tierra] el $k$ $b b-\check{s}$ y la ŷallābiyya.

[[Los notarios (muwattiqūn) dieron por lícito que el quintero pusiera como condición al dueño de la tierra el $k]]-b b-\breve{s}$. Esto lo establecieron algunos šayjs del Libro de la Mudawwana dentro del Capítulo de la Sociedad (Kitāb al-šarika). [Nuestros] šayjs [han llegado a determinar la licitud de esta condición] tras establecer una analogía $(q \bar{a} s a)$ con la obligación que tiene el dueño de la tierra de proporcionar al quintero la ŷalläbiyya.

\section{e) Comentario}

La fetua principal que aparece en el texto escrita en el margen se inicia, como es habitual, con el verbo su'ila 'an («se le preguntó sobre»/《fue interrogado por»), seguido del nombre del jurista al que va dirigida esta consulta, al-Qawrī. A esa misma altura del texto hay dos anotaciones: a la derecha, una nota indica que el nombre del jurista consultado es interpretado como al-Qarawī. En la edición de Rabat también se hace referencia en nota que en otro manuscrito se identifica al jurista como al-Qarāwī, en vez de al-Qawrī. Hay que tener en cuenta la similitud formal de los dos nombres: al-Q(a)wrī (al-Qawrī)/al-Q-r-wī (al-Qarawī).

A la izquierda, una anotación que se puede tomar como título de la fetua, «La cuestión del quintero (mas'alat al-jammās)», que sirve de localizador al jurista que consulta el Mi ${ }^{i} y \bar{a} r$.

La fetua empieza con $m \bar{a}$ dākara al-muwațtiqūn... y, aunque se encuentra diez líneas más abajo de donde se cita por vez primera a al-Qawrī, hay que suponer que la consulta está también dirigida al mismo muftí. A esta misma altura del texto figura una nota al margen que parece muy valiosa, no sólo porque contiene la información primordial de este trabajo, sino porque ha sido interpretada de una manera muy diferente tanto en la edición de Rabat como por V. Lagardère en su Histoire et Société. Considero que, en realidad, la nota al margen es otra consulta, escrita en ese lugar aprovechando la similitud de la cuestión y que queda respondida con la misma información que se ofrece en el texto marginado. Por ese motivo y a falta del nombre del muftí al que va dirigida la nueva consulta, hay 
que poner en duda, incluso, que el autor de esta fetua marginal sea al-Qawrī.

En la edición de Rabat, a diferencia de esta interpretación, el texto escrito fuera del margen se inserta en el que está marginado, como si esta anotación lateral formara parte de una única fetua y hubiera sido el olvido del copista el motivo por el que dicho texto se encontrara escrito fuera. En este caso, pienso que no es así porque el texto escrito en los márgenes, sin incorporarle esta anotación, es totalmente autónomo. Es una información completa acerca de si es legal que el quintero exija la ŷallābiyya y el salhām al dueño de la tierra. Y, basándome en ello, insisto en señalar que el texto que se escribe al margen es una nueva fetua, que tiene como objeto exponer la legalidad del quintero al exigir el $k-b b-\check{s}$ al dueño de la tierra y que para su planteamiento se aprovecha el texto ya existente y la información dada. Por esta razón, se puede considerar que la prenda de ropa que responde al término $k-b b-s ̌ s$ es lo suficientemente parecida a la ýallābiyya como para establecer una analogía con ella $\mathrm{y}$, del mismo modo, lo suficientemente diferente a ella como para haber sido necesario emitir una nueva fetua.

Se puede ver en la edición facsímil como, incluso, para comprender mejor el texto que queda al margen, se ha escrito parte de una palabra en el texto lateral $(a l-k) \mathrm{y}$, tras una línea llevada hacia afuera, ésta es terminada $(b b-\breve{s})$. Desde aquí parte el desarrollo de la segunda fetua, tal y como lo he interpretado y, como señalaba antes, es totalmente distinto a como se ha visto en la edición de Rabat, ya que aquí la nota está incluida en la otra fetua del texto escrito en los márgenes. Por ese motivo, hay que considerar que el dictamen jurídico no es interpretado de forma correcta en la nueva edición del Mi yār, ya que, además de no estar reflejado todo el texto de la edición de Fez y no explicar nada de estas anotaciones marginales, la fetua resultante tiene matices distintos. Así pues, en la edición de Rabat los notarios consideran lícito que el quintero le exija al dueño de la tierra el $k-b b-\check{s}$, según habían establecido las autoridades de la Mudawwana y según se había reglamentado estableciendo una analogía con respecto a la ŷallābiyya y el salhām. En la edición de Fez, la analogía se establece únicamente con respecto a la ŷalläbiyya. Del mismo modo, la edición de Rabat hace suponer que en la $M u$ dawwana algunos maestros encuentran la licitud de la consulta comparando el $k-b b-\check{s}$ con las otras dos prendas, a diferencia del de la 
edición litografiada de Fez que sólo habla de la Mudawwana cuando se refiere al $k-b b-\check{s}$.

Aunque resulta extraño, lo cierto es que la Mudawwana no cita ninguna de las tres prendas en su Kitāb al-šarika o «Capítulo de la sociedad ${ }^{20}$, tal y como se comenta en esta fetua, ni tampoco hay noticias de ellas en otros capítulos que abordan los contratos agrícolas, como son el «Capítulo del alquiler de casas y de tierras» y el «Capítulo de la musāqat o contrato de aparcería en tierras de regadío» ${ }^{21}$.

Por otra parte, se afirma en el texto que al Qawrī encuentra lícito que el aparcero exija la ýallābiyya al dueño de la tierra, tal y como quedaba reflejado en las actas notariales de su época y, ya que la fetua que se escribe al margen aprovecha esta misma frase, aunque, como señalábamos antes, es bastante dudoso que vaya dirigida al mismo muftī, también se podría interpretar en el texto que los documentos notariales reflejan «la licitud de la exigencia del $k$ $b b-\check{s} \gg$. Lo cierto es que los formularios notariales de los que disponemos hasta la fecha no ofrecen datos de ninguna de estas dos pren$\operatorname{das}^{22}$.

${ }^{20}$ Ibn al-Qāsim, al-Mudawwana al-kubrà (recensión de Saḥnūn), Beirut, s.d. (Reimpr. offset), El Cairo, 1923, t. II, vol. VI, 40-85.

${ }^{21} \mathrm{He}$ consultado detenidamente estos capítulos, conjuntamente con el «Capítulo de la Sociedad», con motivo de la elaboración de mi tesis doctoral. Véase Ibn al-Qāsim, al-Mudawwana, t. XI, vol. VI, 147-201, para el «Capítulo del alquiler de las casas y de las tierras»y t. XII, vol. VI, 2-25, para el «Capítulo de la musāqat».

${ }^{22}$ No hay noticias de la yalläbiyya ni del $k-b b-\check{s}$ en ninguno de los siguientes documentos notariales: Abū Isḥāq al-Garnāțī, al-Wațā'iq al-mujtașara, M. Naŷī (ed.), Rabat, 1988; Ibn al-'Aț̣ār, Kitāb al-Wațā'iq wa-l-siyillāat, P. Chalmeta y F. Corriente (eds.), Formulario notarial hispano-árabe, por el alfaquí y notario cordobés Ibn al'Atțār (s.X), Madrid, 1983; idem, Formulario notarial y judicial andalusí, P. Chalmeta y M. Marugán (eds.), Madrid, 2000; Ibn Mugìt, al-Muqnie; Cano Ávila, P., Contratos conmutativos en la Granada nazari del siglo XIV, según el Formulario notarial de Ibn Salmūn (m. 767/1366), Tesis Doctoral, Universidad de Granada, 1986, editada en microfichas por el Servicio de Publicaciones en 1987; 'Abd al-Wāḥid al-Marrākuš̄̄, Wată 'iq al-murābițīn wa-l-muwahhidìn, H. Mu'nis (ed.), Rabat, 1997 (en realidad, se trata de los Formularios notariales de Abū Muhammad 'Abd Allāh b. 'Abd al-Wāḥid al-Fihrī (al-Buntī, m. 462/1070), Wațā'iq wa-l-masā'il al-maŷmū'a, según concluye Aguirre, J., "Notas acerca de la proyección de los kutub al-wațā'iq en el estudio social y económico de al-Andalus", MEAH, Sección Árabe-Islam, 49 (2000), 9, n. 14. De las tres prendas que se tratan en este trabajo, sólo se cita una de ellas con nombre parecido, la silhāma o "manto con capucha», en el formulario notarial de al-Ŷazīiñ, al-Maqșad al-mahmmūd fì taljīs al-'uqūd, A. Ferreras (ed.), Madrid, 1998, 238 ár. (trad. en su intro., 48-49). Véase infra un comentario más elaborado de este documento notarial.

Al-Qanțara (AQ) XXX 2, julio-diciembre 2009, pp. 447-465 ISSN 0211-3589 
Las dos consultas que se tratan aquí son respondidas por el muftí utilizando algunos de los métodos a los que su condición le obliga. Como bien señala F. Vidal, «para dictaminar fetuas existe una jerarquía y orden de preferencia en la consulta de obras y en la elección de la opinión del maestro dentro de la escuela malikí»» ${ }^{23}$. El mismo al-Wanšarīsī expone en el Mi yār el método a seguir:

Sólo se ha de emitir fetua según la opinión de Mālik en el Muwațta' y, si no se encuentra en el caso determinado dentro de esta obra, se buscará su parecer en la Mudawwana. Si tampoco se encuentra la opinión de Mālik en esta obra, se escogerá la opinión de Ibn al-Qāsim en la misma y, de no hallarse, se buscará su opinión en cualquier otro lugar. Si no resulta la búsqueda, se tomará la opinión de otro autor recogida en la Mudawwana y, por último, si no diera fruto todo esto, se optará por las opiniones de otros maestros de la escuela $^{24}$.

Partiendo de que las dos fetuas son emitidas por el mismo muftí, el desarrollo de la misma sigue las directrices que marca alWanšarīsī de la siguiente manera:

Inicialmente, y sólo para la fetua escrita en el margen, al-Qawrī busca referencias en la obra jurídica del qayrawānī Saḥnūn, al-Mudawwana al-kubrà (s.vIII). Como se puede apreciar, las opiniones de los sabios juristas que fueron incluidas en la Mudawwana son tomadas en esta fetua como máxima autoridad. Sin embargo, tal y como señalé antes, no he encontrado en los capítulos que regulan el mundo rural de esta obra ninguna referencia a la prenda $k-b b-\check{s}$ ni a ninguna otra ropa perteneciente al quintero.

En la fetua escrita al margen vemos que los maestros aprueban que el quintero exija el $k$-bb-š por la analogía (qiyās) que existe con la ŷallābiyya. En la edición de Rabat, al haber incorporado el texto que queda al margen, se interpreta, por el contrario, que la analogía se establece no sólo con la ŷalläbiyya sino también con el salhām. Ambas prendas son consideradas legales por la mayoría de los jurisconsultos musulmanes en el contrato de jamāsa, según se aprecia en el texto marginado.

${ }^{23}$ Vidal Castro, F., "El muftī y la fetua en el derecho islámico. Notas para un estudio institucional", Al-Andalus-Magreb, VI (1998), 312.

${ }^{24}$ Al-Wanšanīīi, al-Mi yōar, Rabat, XII, 23. La traducción del texto es de Vidal Castro, "El muftī y la fetua", 313.

Al-Qanțara (AQ) XXX 2, julio-diciembre 2009, pp. 447-465 ISSN 0211-3589 
Posteriormente, en esta fetua escrita dentro del margen se cita la obra en la que al-Qawrī ha basado su respuesta, aunque sólo en ella se legaliza la exigencia de la ŷalläbiyya: el Taqyīd 'alà l-Mudawwana del šayj Abū 'Imrān Mūsà al- 'Abdūsī, de la que no se ha encontrado ninguna información ${ }^{25}$. Ciertamente, era muy usual que los alfaquíes acabaran por escribir su propio manual y que los hombres de leyes los utilizaran como manuales de aplicación totalmente válidos. En este caso, se trata de un comentario de la Mudawwana, en donde, sin duda, se citaría algo sobre la ropa del quintero, según la declaración del propio 'Isà b. 'Allāl en esta fetua.

El dictamen que pronuncia al-Qawrī para la fetua que está fuera del margen tiene también como base otro dictamen promulgado años antes por Ibn 'Allāl, imam de al-Qarawiyyīn y cadí de Fez (823/1420-1), quien no se decide a dar por lícita la condición del quintero de exigir esta indumentaria, sino que se limita a dar dos opiniones contrarias entre sí: la primera de ellas tiene como origen la misma obra de Mūsà al-'Abdūsī, Taqyīd 'alà l-Mudawwana, en donde se confirma de nuevo la aprobación de este jurista para que se le proporcione la ŷlläbiyya al quintero, mientras que la segunda opinión que ofrece pertenece a otro jurista llamado Abū 1-'Abbās alQabbāb (708/1310) que se remonta un siglo y medio atrás. Este šayj de Fez se opone totalmente a que el quintero exija ropas al dueño de la tierra y así lo difundió (a lama-hu ${ }^{26}$ en su ciudad, según Ibn 'Allāl. En esta fetua de al-Qawrī no se citan las fuentes en las que al-Qabbāb se basa para emitir su opinión.

Partiendo, no sin reservas, de que las dos fetuas pertenecen a alQawrī, podemos decir que, según los conocimientos que demuestra te-

${ }^{25}$ Algunos datos sobre Mūsà al-'Abdūsī se hallan recogidos en la Mawsū'at a' lām alMagrib = Dictionnaire des célébrités marocaines, M. Hâ̂ŷ̄i (coord.), Beirut, 1417/1996, II, 684-685, pero en ninguna de las tres referencias que se recogen de este autor se cita la obra en cuestión. Tampoco he obtenido resultados satisfactorios al respecto en Brockelmann, C., Geschichte der Arabischen Litteratur, Leiden, 1937 (Sup. I) y 1942 (Sup. III), ya que no se recoge más que un autor, registrado en Sup. III, 530, citado como 'Abdūsī, y nos remite a Sup. I, 599, sin resultados. También se registra una obra con el mismo título Taqyìd 'alà l-Mudawwana encontrada en Sup. III, 1125, que nos conduce a Sup. I, 30016, cuyos escasos datos no nos proporcionan ninguna solución. Asimismo, se echa de menos el autor y su obra en Muranyi, M., Dirāsāt fì mașādir al-fiqh al-mālikī. Studies in early malkite literature, M.F. Hiyyazī (ed.), S. Buhayrī (trad.), Beirut, 1409/1988.

${ }^{26}$ En la edición de Rabat el verbo 'alama-hu es sustituido por a'mala-hu, con una clara metátesis. Se interpretaría, en vez de «darse a conocer, difundir», como «aplicarse, ponerse en práctica». Véase ed. Rabat, 151; ed. Fez, 97.

Al-Qanțara (AQ) XXX 2, julio-diciembre 2009, pp. 447-465 ISSN 0211-3589 
ner en ellas, unido a su cualificación científica y su nivel intelectual, este jurista forma parte de un grupo determinado de mufties, según las Fatāwà de Ibn Rušd ${ }^{27}$ que, de acuerdo con la sistematización realizada por F. Vidal ${ }^{28}$, se caracterizan por actuar de la siguiente forma:

Adquieren sus conocimientos a través de las fuentes de su escuela, la mālikí.

Conservan las sentencias de sus maestros sobre cuestiones de fiqh y estudian y analizan su contenido jurídico.

Llegan al nivel de investigación por el conocimiento de la analogía (qiyās) entre aplicaciones y principios.

Por último, sólo queda citar las fuentes que utiliza al-Qawrī para emitir sus dictámenes. Cronológicamente, son las que siguen: SaḥnūnIbn al-Qāsim, al-Mudawwana al-kubrà (s. vIII); Abū l-'Abbās Aḥmad b. Qāsim al-Qabbāb (Fez, m. 708/1310); Abū 'Imrān Mūsà b. Muhammad b. Mu'tī al-'Abdūsī (Fez, m. 776/1374), Taqyīd 'alà lMudawwana y Abū Mahdī 'Isà b. 'Allāl al-Kutāmī al-Mașmūdī alFāsī, al-Qarawiyyīn/Fez (m. 823/1420-1421).

\section{La traducción de Lagardère}

Lagardère ha traducido parcialmente estas dos fetuas en su Histoire et société ${ }^{29}$. Como se ha dicho anteriormente, aparte de tomar como base la edición de Rabat y considerar que se trata de una sola fetua en vez de dos, se aprecian errores en su interpretación y traducción.

Su traducción dice así:

Quid du colonat partiaire au quint (mas'alat al-hammās)? [...] Les notaires (al-muwattiqūn) admettent que le quintenier impose au propriétaire la fourniture d'une houe (al-kabš, sic $)^{30}$, d'une blouse (Ğallābiyya) et d'un manteau á capuchon (silhām), d'après Abū 'Imrān Mūsà al-'Abdūsī dans son "Taqyìd 'alà l-Mudawwana». 'Isà b. 'Allāl a rendu une fatwà conforme à l'opinion de ce dernier disant: "Notre

${ }^{27}$ Ibn Rušd, Fatāwà, III, 1500-1502.

${ }^{28}$ Vidal Castro, "El mufti y la fetua", 309-310.

${ }^{29}$ Lagardère, Histoire et société, 333-334, nº 178.

${ }^{30}$ Véase Dozy, Dictionnaire détaillé, II, 448, s.v. kābša, «instrument pour labourer les arbres, houe». Cfr. ibidem, s.v. kabbūš̄i

Al-Qanțara (AQ) XXX 2, julio-diciembre 2009, pp. 447-465 ISSN 0211-3589 
šayh Abū 'Imrān al-'Abdūsì déclarait licite la fourniture d'une blouse (乌̆allābiyya) au quintenier, conformément aux dires des rédacteurs d'actes (ahl al-watā'iq), tandis que notre šayh Abū l-'Abbās al-Qabbāb l'interdisant.

Expuesta su versión de la fetua, son detectables las siguientes imprecisiones:

Lagardère no aprecia la šadda de la consonante $b \bar{a}$ ' de la edición de Fez y lee $k a b s ̌ s$, en vez de $k-b b-\check{s}$, tal y como se interpreta en la edición de Rabat. Este término lo traduce por «houe», «azada o azadón» ${ }^{31}$. En primer lugar, no parece probable que el quintero, además de dos prendas de ropa, tal y como lo ha traducido Lagardère, exija una azada, ya que los instrumentos que necesita el jammās siempre son aportados por el dueño de la tierra según se aprecia en todos los contratos de la muzāra'a al quinto y en donde, como ya se ha señalado, el aparcero únicamente contribuye con su trabajo. Del mismo modo, parece poco factible que el quintero necesitara para la siembra, el cuidado o la recogida de granos, el uso de una azada, más indicada y usual en el cultivo de verduras, hortalizas y árboles frutales.

Por otra parte, disponemos de un documento similar a éste de alMi'yār en el que me apoyo para rechazar que el $k-b b-\grave{s}$ se trate de un instrumento agrícola: un acta notarial de al-Ŷazīrī sobre un contrato de aparcería ('aqd îyāra harrât $)^{32}$. En este escrito consta que el dueño de la tierra está obligado a dar al aparcero comida y ropas durante el tiempo que dure su trabajo en ella. El arrendatario tiene que recibir una aljuba de lana del país ( $\hat{y} u b b a$ süf baladī), un manto con capucha (silhāma), una trusa o especie de calzoncillo (tubbānn), un par de alpargatas con suela de cuero (hirkāsatāni mun'alatāni), dos amengos $^{33}$, especie de zapatos (aminqāni) y polainas (tarbūqāni). Este

${ }^{31}$ Lagardère, Histoire et société, $333, \mathrm{n}^{\circ} 178$, y compárese con al-Mi'yār, ed. Rabat, 150; ed. Fez, 97.

${ }_{32}^{32}$ Al-Ŷazīīi, al-Maqșad, 238 ár. (trad. en su intro., 48-49).

33 «*Amengo» es una forma hipotética proveniente del romandalusí *ANT+AMÁ/ $I N K(O)$, «(pieza) delante del calzado» < bajo latín *amincum, retroformado sobre el latín amiculum. En castellano ha dado «tamango», «calzado rústico de madera o cuero». Véase, Corriente, F., Diccionario de arabismos y voces afines en iberorromance, Madrid, 1999, 450, s.v. tamango. Agradezco a F. Corriente la aclaración de este término «amengo». 
trabajador no percibe del propietario ningún instrumento de labranza, como creo nunca recibió el quintero.

Asimismo, Lagardère obvia en su traducción el verbo $q \bar{a} s a$ («comparar una cosa con la otra, establecer una analogía») existente en las dos ediciones del Mi yār y que es fundamental, en mi opinión, para entender correctamente esta(s) fetua(s). Si la cuestión que se le plantea a al-Qawrī es la licitud o no de la exigencia al dueño de la tierra por parte del quintero de un $k-b b-s ̌$ y dicha consulta es contestada por medio de qāsa 'alay-hi l-šuyūj..., es evidente que la respuesta del muftí se apoya en la analogía (qiyās), según habían establecido anteriormente para casos similares algunos šayjs. De esta forma, comparando en la fetua marginal el $k-b b-\check{s}$, la ýallābiyya e, incluso, el silhām, nos hace suponer que gozaban las tres de características comunes y, por ello, podemos dar por válido que el $k-b b-\check{s}$ pertenece a la indumentaria del quintero y no admitir que es un azadón, tal y como señala Lagardère.

De igual modo, para el investigador que no consulte las fuentes o para el no arabista, esta traducción le puede llevar a un error, aún sospechando que el $k-b b-s ̌$ en realidad formara parte de la vestimenta, ya que Lagardère interpreta la cuestión como si se tratara de la licitud de que goza el quintero para exigir las tres prendas de ropa conjuntamente. En realidad, como se ha señalado, no es así. Así pues, esta imprecisión de la traducción llevaría a considerar que cada una de estas prendas tiene unas características distintas y que el jammās necesita de las tres por la variedad de sus prestaciones. Distinto es considerar que éstas no se exigen juntas y que el $k$ - $b b-\check{s}$ pudiera tener características formales parecidas o idénticas a las del silhām o de la ŷalläbiyya. Por otra parte, se supone que estas dos últimas se podrían exigir tanto juntas como por separado, tal y como podemos apreciar en la penúltima frase de esta fetua cuando se señala que Abū 'Imrān Mūsà al'Abdūsī consideraba legal que el quintero exigiera (como única prenda) la ŷallābiyya.

Por último, y no menos importante, hay que señalar que Lagardère se equivoca al atribuir esta fetua al muftí de Cairuán, Abū 'Ali al-Qarawī (234/849), ya que es imposible que siendo éste un jurista del s. IX pueda basar su dictamen en juristas de los s. XIV y XV. Seguramente el error vino a propósito de una nota existente en la edición de Rabat que dice que en una copia de la obra así se señala o, 
quizá, debido a la nota que hay en el margen derecho del Mi'yār en su edición de Fez, que igualmente así lo expresa. No obstante, podía haber pensado, por lógica, aunque fallando igualmente, que se trataba del jurisconsulto del s. XIv, 'Abd al-'Aziz al-Qarawī (Fez, m. 750/1349), cuya fetua él mismo traduce en su obra Histoire et Société $^{34}$.

\section{Conclusión}

Las dos fetuas del s. XV recogidas en al-Mi yār de al-Wanšarīsī pretenden regular una costumbre que se venía imponiendo en el Magreb y, por extensión, en al-Andalus, que era la de exigir una determinada ropa por parte del quintero al dueño de la tierra en la que aquél trabajaba. Las tres prendas citadas en estos dictámenes, que podían ser solicitadas independientemente, como ya se dedujo en este trabajo, vienen a cubrir el cuerpo de un aparcero sin recursos, quien no puede aportar en la sociedad que establece con el propietario de la finca nada más que su trabajo. A cambio recibirá la quinta parte de la cosecha resultante. Esta forma de contrato, en principio ilegal para el Islam, es permitida por los juristas musulmanes, quienes amoldarán sus leyes a las necesidades socio-económicas del momento y a las costumbres del lugar. Como vemos en estas fetuas, los muftíes consideran lícita la jamāsa, ya que determinan que se trata de una sociedad, aunque de hecho no lo sea. Y se puede considerar que no lo es, básicamente, por el desequilibrio existente entre las aportaciones de los dos socios, por el abuso con el que es tratado el quintero al exigirle hacer más trabajos que los agrícolas propios de la cosecha y por la obligaciones impuestas al dueño de la propiedad, como ésta que se reglamenta en la fetua, en la que se normaliza la concesión de una ropa a su «socio». Estas fetuas, tan ricas en información, han sido hasta la fecha mal interpretadas en la edición moderna de Rabat. En ella no se tiene en cuenta en su totalidad el texto escrito fuera del margen de la edición antigua de Fez, un texto lateral que es acomodado al que estaba marginado sin ningún criterio por parte del editor, quien tampoco ofrece alguna nota explicativa de su procedimiento. El resultado es un tex-

${ }^{34}$ Lagardère, Histoire et société, 474, no 49.

Al-Qanțara (AQ) XXX 2, julio-diciembre 2009, pp. 447-465 ISSN 0211-3589 
to reducido y erróneo. De este texto tan diferente al original parte la traducción e interpretación de V. Lagardère. Por ello, en vista de las diferencias existentes entre las ediciones antigua y moderna de al$M i^{i} y \bar{a} r$, considero que sería conveniente que se realizara una edición crítica de esta obra.

Recibido: 30/05/2006

Aceptado: 07/06/2007 